\title{
Reflection on Quality Assurance System of Higher Vocational Education under Big Data Era
}

\author{
Xinlan Jiang ${ }^{1,2}$ \\ ${ }^{1}$ School of Education Administration, Guizhou University of Finance and Economics, 550025 Guiyang Guizhou, China \\ ${ }^{2}$ Educational College, Shandong Normal University, 250022 Ji'nan Shandong, China
}

\begin{abstract}
Big data has the features like Volume, Variety, Value and Velocity. Here come the new opportunities and challenges for construction of Chinese quality assurance system of higher vocational education under big data era. There are problems in current quality assurance system of higher vocational education, such as imperfect main body, non-formation of internally and externally incorporated quality assurance system, nonscientific security standard and insufficiency in security investment. The construction of higher vocational education under big data era requires a change in the idea of quality assurance system construction to realize the multiple main bodies and multiple layers development trend for educational quality assurance system, and strengthen the construction of information platform for quality assurance system.
\end{abstract}

Keywords. big data; higher vocational education; quality assurance system

With the development of higher education, either in the number of schools or the students scale and market demand, the Chinese higher vocational education accounts a consideration proportion in higher education system, which is significant for the development of social economy. It is mentioned in Decisions on Facilitate the Development of Modern Vocational Education by State Council in May 2014 that, a modern vocational education system with Chinese character and global class will be formed in 2020; Construction and Planning of Modern Vocational Education System (2014-2020) issued in China in June 2014 proposed the purpose and requirement for higher vocational education, and mentioned that "Improve the talent cultivation system based on cooperation of school-enterprise and work-study, and perfect the assessment system for vocational education quality. Establish an assessment system for vocational education quality by taking the professional ethics, technical and skill level, and the employment quality as the core. Vocational colleges shall establish an internal quality assessment system to strengthen the construction of quality assurance system. How to realize the requirement of Construction Planning, construct an education quality assurance system for higher vocational education applicable to Chinese characteristics and era demand as soon as possible have a great impact on the development of higher vocational education.

The word "Big data" has become one of the most widely used words in each world currently. Big data, mobile Internet, intelligent manufacture have jointly been called as the three major sub-reverse technologies in the information field. With the arrival of "Big data" era, how will the quality assurance system of higher vocational education adapt itself to the era features of big data? How will the construction of quality assurance system for higher vocational education be faced with? How to get the help of advanced technical development to realize the possibility for macro group changed into micro group in the construction of higher vocational education quality? This article attempts to discuss the response to the construction of quality assurance system of higher vocational education in the big data background.

\section{The concept and era value of big data}

2013 is called the beginning year of Chinese big data, when the government greatly supported the development of big data. In Chongqing, Beijing, Dalian and Guizhou were respectively issued the plans related to the development of big data. China Scientific Institution, Fudan University and other organizations have successively established nearly ten special organizations for scientific data research. China Communication Association and China Computer Association respectively established the expert committee of big data to facilitate the scientific research and development of Chinese big data.

\subsection{Connotation of big data}


There's no uniform concept for what is big data in the academic field. Generally, the big data is considered as the data integration that cannot be abstracted, treated, managed or sorted in a certain reasonable time by current mainstream tools to be used for business decision-making and management in the enterprises due to excessively large scale of information and data to be collected, which is also called massive data. As for the definition of Gartner research organization: "Big data" will not become the informational assets with large amount, high increase rate and variety, as well as stronger decision-making, insight and procedure optimization abilities until it has a new treatment mode. The big data mainly has two major types: Firstly, it is the intensive "extremely large" or "massive data" produced by products and services of the enterprise itself. Secondly, it is the big data of network, generally referring to the big data with rich and discoverable social, commercial or scientific research values which occur in the Internet. ${ }^{[1]}$ It can be seen in the development of big data, it is not a suddenly emerged new matter, instead, it has the same source with the previous data mining and data explosion. Big data is more of a phenomenon gradually derived from the constant increase of data volume and types than simply a technology. ${ }^{[2]}$

The difference of big data and traditional data includes: The traditional data is basically structured, instead of personalized. Since 2012, non-structural data will account for over $75 \%$ of the whole Internet data volume. Big data is generally related to hot topics like data analysis and mining, commercial intelligence, data warehouse and cloud calculation. ${ }^{[3]}$

\subsection{Features of big data}

The features of big data are generalized by $4 \mathrm{Vs}$ (namely volume, Variety, Value and Velocity) in the academic field.

1. Volume. It refers to the massive data volume and integrity of its scale. Currently, the data volume has developed from TB (1012 bits) to $\mathrm{PB}$ or even $\mathrm{ZB}$, which can be called as numerous, massive or even considerable volume. 2. Variety. It has a lot of data types, divided into structured data and non-structured data. Compared to the previous structured data based on text easy for storage, the non-structured data has become more and more, including information of network log, audio, video, picture, geographical position. The multiple types of data proposed a higher requirement on the data-to-data treatment ability. 3. Velocity. This is the most obvious feature by which the big data is distinguished from the traditional data. Velocity mainly presents itself in mobility of data flow and big data. 4. Value. Value indicates the real meaning of big data application. Its value has the scarcity, uncertainty and variety.

The feature of big data determines the wide application of big data in future fields. The future big data will be widely applied in many fields like education, energy, traffic, public security, Internet and communication. The deep incorporation of big data application with higher education quality assessment has become the main trend in the educational field. As for the construction of quality assurance system for higher vocational education, in the "big data" era, with the surge of data and gradually perfection of informational network construction, people will have a deeper understanding for each level and links in the higher vocational education process, which proposed a new challenge for construction of quality assurance system.

\section{Main problems in construction of qua- lity assurance system for higher voca- tional education}

The word quality assurance originates from the western enterprise field from late 1950 s to early 1960 s, and applied in the higher educational field from late 1980s to early 1990s. Mainly refer to the systematic and planned activities implemented in the quality system according to demand. ${ }^{[4]}$ The internal and external demand faced in the university results in the production of quality assurance, as thought by Anna Rance Dell, the deputy headmaster of Oxford University " Firstly, it is the internal demand of university, namely the demand of management and provision of healthy environment for teachers and students; Secondly, it is the external demand, namely the external university shall formulate a set of publicly recognized standards to grant corresponding qualification and degree for university., $[5]$ The interrelationship among each element formed in the process of quality assurance is the quality assurance system. Higher vocational education is the component of higher education, so its connotation of quality assurance is the same.

In the big data era, the talent cultivation mode, teaching mode, teaching content and means, knowledge exchange and treatment mechanism will be subject to corresponding changes, which will directly have an impact on the development of higher vocational education quality. However, Chinese current quality assurance system for higher vocational education followed the assurance system mechanism in the planning economy era, which presented the inadaptation to the big data era.

\subsection{Imperfect main body of assurance}

Government, school and enterprise are the three main bodies of value for higher vocational education quality. So the quality assurance system of higher vocational education shall be constructed and operated by those three main bodies. But the current main body of Chinese quality assurance system for higher vocational education is the government, and the participation rate of industrial enterprises is not high, and school has lost its status of main body in the quality assurance. The assurance is mainly led by government, which is the absolute authority. Each higher vocational cultivation unit is under the nationally uniform quality standard, and the costs of issuing and cultivation of discipline setting, recruitment index are all uniformly allocated by our country. The school basically accepts the relevant educational assessment from governmental organization passively, so the effect of school quality assurance system is limited. Furthermore, the higher vocational education has not formed 
a reasonable third-party quality assurance organization, and the education, third-party organization and teachers and students seldom participate in the quality assurance process, so the impact is limited, too. And they are not sorted and assured in accordance with different talent cultivation specifications, different types of schools or different types of disciplines in the process of quality assurance.

\subsection{The internal and external incorporated quali- ty assurance system of higher vocational extern- al based on external quality assurance is not formed}

As the component of higher education, the higher vocational education shall firstly focus on its educational property, namely the knowledge orientation is its important value orientation, followed by its technical property. As for vocational education, the knowledge orientation shall first involve the great change in knowledge in the vocational education field, followed by the selection of knowledge content and the relation between knowledge and study. ${ }^{[6]}$ Therefore, The quality assurance system of higher vocational education shall be an internal and external incorporated system, not only in compliance with the internal standard of educational quality "People are the purpose", but also the internal logic of technical system development, which may reflect the essential features of educational and technical properties of vocational education system. Therefore, the modern quality assurance system of vocational education shall assure the internal standard for knowledge culture, as well as meet the external standard of demand of technical industrial structure layout on talents. This will require sufficient autonomy for higher vocational education to carry out construction of internal quality assurance system in quality assurance. Meanwhile, it shall actively adapt itself to the external quality assurance system to form the internal and external incorporated quality assurance system, and create a better external assurance conditions for development of higher vocational education. While in the current construction of quality assurance system for higher vocational education, it focuses on the external quality assurance, and the government plays a very important role in the external quality assurance system, which restricts the functions of internal quality assurance system for higher vocational education. Originally, the purpose of governmental external quality assurance was to facilitate the construction of internal quality assurance system in university by "assessment facilitating the promotion, assessment facilitating the construction, incorporation of assessment and construction", while in the practice, the school just passively carried out assessment according to the requirement of government assessment, usually doing what the government would assess, which reflected a strong utilitarian, caused hidden troubles for improvement of higher vocational education quality, as well as the low efficiency of quality assurance for higher vocational education.

\subsection{Non-scientific quality standard}

The quality standard is an important reference for quality assurance, and also an important means to assess the level of higher vocational education quality. The non-scientific quality standard of higher vocational education includes, first, the non-integrity and non-systematic quality standard. Currently, there are standards set in Chinese schools, but lacking the standards of professions, subjects, teaching resources, training and practice that directly impact the educational quality; Secondly, it is the mismatch of quality standards, especially the professional qualification standards issued by labor department and industrial enterprises, which makes the higher vocational colleges uneasy to select; Thirdly, it is the design insufficiency of process standards for quality assurance. For the convenience of assessment, our country just used one quality assurance standard for national education quality of higher vocational education as it designed the standards instead of designing different quality assurance index system according to directly types of schools, different types of disciplines or different requirement on items.

\subsection{Undesirable quality assurance and costs assurance}

Chinese vocational education investment is insufficient, which will definitely have an impact on the construction of quality assurance system for higher vocational education. The construction of quality assurance system is a large systematic project requiring large investment, theoretical research, organizational construction, standard formulation, research and production of assessment plan, implementation of assessment organization, database construction of teaching status, issuing of monitoring report that shall need a certain amount of costs. But currently, these costs are scarce, or even none.

\section{Response to the construction of quali- ty security system of higher vocational education in the big data background}

The arrival of big data era will result in reform of educational idea, including newly imposed requirement on education and teaching mode, quality improvement and quality assurance As an important base for cultivation of skill-type talents required for social economy, the higher vocational education shall squarely face the advent of big data era, reflect in the construction process of quality assurance system, and keep pace with the time by constructing the assurance measure and informational platform.

\subsection{Change the idea of construction of quality as- surance system, and establish the quality assurance idea to adapt to the development of big data era}

Big data has a deep impact on all aspects of education in the teaching and management of foreign education, the deep mining of educational data for improvement of educational quality and teaching management has become a main method, which is subject to further devel- 
opment. For students, it is possible for big data to predict and assess the accuracy of study status for students. This trend has deepened the mutual understanding between teachers and students, schools and students, society and schools, as well as schools and government. American schools are able to predict the enrollment rate in $85 \%$ accuracy based on the analysis of student data. ${ }^{[7]}$ China is now in the social transformation period, so the big data will play an active role in the determination of teaching and study method for Chinese education, as well as the monitoring of teaching assessment and teaching quality, by which the educational quality assessment will face an innovative change. "Big data" makes it possible to carry out single procedural assessment. Furthermore, the detailed performance of students in the study and research process will be formed into data, which will be sorted, arranged, counted and analyzed to form the quality assessment method for study and research of higher vocational education. The process of school-running, teaching, scientific research audition of teachers will also be realized by the similar methods. Organization of Economy and Cooperation Development (OECD) in 2013 proposed in For Facilitation of Better Study: International Perspective of Assessment and Evaluation a new thought "Intensify the assessment to promote the students study". In evaluation, the assessment will be kept consistent with the educational purpose, and it is thought to take the "students as the importance of core and assessment" into the procedural assessment of improving the classroom practice. ${ }^{[8]}$

In this background, we shall transform the construction concept of quality assurance system for higher vocational education. In the construction of quality assurance system, we shall use the advanced assurance idea to lead the construction of data management platform. The higher vocational colleges shall take the data management platform as the important means and way for school management, as well as take the management platform construction as the opportunity to focus on construction of teaching teams for professional construction and incorporation, construction of teaching quality assurance system, so as to constantly perfect the management system, strengthen the management structure, comprehensively improve the talent cultivation quality and realize the innovation of management mode, for the purpose of constructing a quality assurance system adaptable to the big data.

\subsection{Realize the multiple main bodies and multiple layers development of quality assurance system for higher vocational education}

Big data era makes it possible to realize the multiple main bodies and multiple layers development of quality assurance system for higher vocational education. In the big data era, the personalized and accurate education will be possible, and assessment for students will be based on the data of their previous study behaviors, which enables us to timely and efficiently understand and regulate the research demand and research efficiency of students, and to efficiently assess the study result; For government and society, it'll enable us to make an analysis on the higher vocational education in university through scientific research and teaching data of schools as well as other relevant information. So, based on which, we can establish an assurance system that the government, schools, teachers and students, and society will jointly participate in, as well as facilitate the coordinating development of internal and external assurance system. The multiple-layered, mutually incorporated quality assurance system from the interconnection of the above assurance main bodies completes the assurance process of higher vocational education quality.

\subsection{Strengthen the information platform construction of quality assurance system for higher vocational education}

The quality assurance information system is the main component of quality assurance system for higher vocational education, which provides a reference to efficiently carry out the quality assessment for higher vocational education. In the big data era, we may use the quality assurance information standard of construction specification for big data technology, establish an information exchange platform among different main bodies of quality assurance system, and strengthen the publicity and fairness of quality assurance system. The advanced management of quality assurance information platform will definitely provide the timely, accurate and comprehensive quality assurance information. In the construction of quality assurance information platform, we shall establish network resources bank, realize resources sharing. The network resources platform is just a database, and also a "intelligence" bank. All the schools may mutually propose questions for data management platform, as well as mutually provide guidance and help. For example, online remote configuration and installation, providing video document to guide the whole process of use, freely providing technical supports. Really encourage the schools to take the construction of data management platform as an important way to propel the schools to change the management mode and method.

\section{Acknowledgement}

Fund project: Periodical fruits of 2014 annual project of National Social Science Fund "Modern university system research based on academic professional perspective" (GN: 14BGL126).This article is also funded by scientific research project of introducing talents in Guizhou University of Finance And Economics in 2013.

\section{References}

1. He Fei \& He Keqing. Discussion on big data and its scientific problem and method [J]. Journal of Wuhan University (Science Edition), 2014, (2):1-11.

2. Geng Qiu \& Meng Jian. Big data era: Opportunity? Challenge? [J] China New Era, 2012, (6):60-61.

3. Jiang Qiping. Advent of big data era $[\mathrm{J}]$. Internet Weekly, 2012, (2):6. 
4. Guo Xin \& Liu Yuanfang. Research on quality assurance system of higher vocational education by Chinese doctors based on perspective of system [J]. Degree and Higher Vocational Education, 2011(9): 1-5.

5. Anna rance Dell. Quality Assurance of Development, Teaching and Study [A]. Collection of Headmaster in Chinese-Foreign University [C]. Beijing: Higher Education Press 2002:249
6. Gong Chunlei. Interpretation of Vocational Education under the Context of Modernity. 2011(3):8-10

7. Yu Changzhi. Possible turning of education in big data era[J]. Jianghuai Forum. 2013(4):189-192.

8. Xie Luyan \& Zheng Mingjiu. Assessment reform of higher education quality in big data era [N]. Chinese Social Sciences Today, 2014-02-16. 